\title{
Neurogenin3 Restricts Serotonergic Neuron Differentiation to the Hindbrain
}

\author{
Abel L. Carcagno, ${ }^{1 \star}$ Daniela J. Di Bella, ${ }^{1 *}{ }^{\oplus}$ Martyn Goulding, ${ }^{2}$ Francois Guillemot, ${ }^{3}$ and ${ }^{\circledR G}$ Gillermo M. Lanuza ${ }^{1}$ \\ ${ }^{1}$ Developmental Neurobiology Laboratory, Instituto Leloir and Consejo Nacional de Investigaciones Científicas y Técnicas (IIBBA-CONICET), Buenos Aires \\ 1405, Argentina, ${ }^{2}$ Molecular Neurobiology Laboratory, The Salk Institute for Biological Studies, La Jolla, California 92037, and ${ }^{3}$ Division of Molecular \\ Neurobiology, MRC National Institute for Medical Research, Mill Hill, London NW7 1AA, United Kingdom
}

The development of the nervous system is critically dependent on the production of functionally diverse neuronal cell types at their correct locations. In the embryonic neural tube, dorsoventral signaling has emerged as a fundamental mechanism for generating neuronal diversity. In contrast, far less is known about how different neuronal cell types are organized along the rostrocaudal axis. In the developing mouse and chick neural tube, hindbrain serotonergic neurons and spinal glutamatergic V3 interneurons are produced from ventral $\mathrm{p} 3$ progenitors, which possess a common transcriptional identity but are confined to distinct anterior-posterior territories. In this study, we show that the expression of the transcription factor Neurogenin3 (Neurog3) in the spinal cord controls the correct specification of p3-derived neurons. Gain- and loss-of-function manipulations in the chick and mouse embryo show that Neurog3 switches ventral progenitors from a serotonergic to V3 differentiation program by repressing Ascl1 in spinal p3 progenitors through a mechanism dependent on Hes proteins. In this way, Neurog3 establishes the posterior boundary of the serotonergic system by actively suppressing serotonergic specification in the spinal cord. These results explain how equivalent $\mathrm{p} 3$ progenitors within the hindbrain and the spinal cord produce functionally distinct neuron cell types.

Key words: hindbrain; neural tube; neuronal specification; serotonergic system; spinal cord; transcription factor

\section{Introduction}

The hindbrain and spinal cord both display a highly conserved pattern of dorsoventral gene expression. Fourteen cardinal populations of neurons have been identified in the spinal cord on the basis of their transcription factor profiles, axonal projections, and neurotransmitter phenotypes (Jessell, 2000; Briscoe and Novitch, 2008; Goulding, 2009). Thirteen of these populations are conserved in the hindbrain (Gray, 2008). Neurons derived from the most ventral progenitor domain, termed $\mathrm{p} 3$, are an exception to this rule with serotonergic (5-HT) neurons generated in the

Received Aug. 11, 2014; revised Sept. 24, 2014; accepted 0ct. 1, 2014

Author contributions: G.M.L. designed research; A.L.C., D.J.D.B., and G.M.L. performed research; M.G. and F.G. contributed unpublished reagents/analytic tools; A.L.C., D.J.D.B., and G.M.L. analyzed data; A.L.C., D.J.D.B., and G.M.L. wrote the paper.

This work was supported by the Agencia Nacional de Promoción Científica y Tecnológica (Grants PICT-2011-1350 and PICT-2009-PRH-72), the International Brain Research Organization (IBRO, Return Home Award) to G.M.L. and the Fogarty International Center, National Institute of Health (Grant FIRCA-NIH 1 R03 TW008026) to M.G. and G.M.L. G.M.L. is an established investigator of the CONICET. We thank Maximiliano Neme for MATLAB script edition and Alejandro Schinder, Greg Lemke, and Micaela Sartoretti for critical comments on this manuscript. We also acknowledge Susana Godoy (Granja Tres Arroyos) for fertilized eggs; Quifu Ma, Domingos Henrique, Shan Sockanathan, Ryoichiro Kageyama, Hermann Rohrer, Tom Jessell, and Lidia Szczupak for plasmids or antibodies; John Rubenstein for Nkx.2.2 mice; Ahmed Mansouri for Uncx ${ }^{\text {IacZ }}$ mice; Jane Johnson for Ascl1 ${ }^{\text {CreeR }}$; and Doug Engel for the Gata2 ${ }^{\text {GFP }}$ line.

${ }^{*}$ A.L.C. and D.J.D.B. contributed equally to this work.

The authors declare no competing financial interests.

Correspondence should be addressed to Guillermo M. Lanuza, Developmental Neurobiology Lab, Instituto Leloir and Consejo Nacional de Investigaciones Científicas y Técnicas (IIBBA-CONICET), Buenos Aires 1405, Argentina. E-mail:GLanuza@Leloir.org.ar.

DOI:10.1523/JNEUROSCI.3403-14.2014

Copyright $\odot 2014$ the authors $\quad 0270-6474 / 14 / 3415223-11 \$ 15.00 / 0$ hindbrain and glutamatergic V3 interneurons in the spinal cord (Briscoe et al., 1999; Zhang et al., 2008; Jacob et al., 2013).

During embryonic development, serotonergic neurons emerge from hindbrain $\mathrm{p} 3$ progenitors that express the transcription factors Nkx2.2, Foxa2, and Ascl1 (Briscoe et al., 1999; Pattyn et al., 2004; Jacob et al., 2007). 5-HT neuron differentiation requires the orchestrated action of Gata2, Lmx1b, and Pet1 (Hendricks et al., 1999, 2003; Cheng et al., 2003; Ding et al., 2003; Craven et al., 2004). In the spinal cord, the establishment of p3 identity also requires Nkx2.2, Foxa2, and Ascl1 (Briscoe et al., 1999; Dessaud et al., 2007; Jacob et al., 2013; this study). However, instead of producing serotonergic neurons, they produce glutamatergic V3 interneurons that selectively express the transcription factor Sim1 (Briscoe et al., 1999; Zhang et al., 2008). Excitatory V3 neurons are components of intraspinal networks that generate organized motor patterns (Zhang et al., 2008; Borowska et al., 2013). In contrast, serotonergic neurons innervate large regions of the brain and the spinal cord, where they modulate a variety of behaviors from anxiety and aggression to breathing and locomotion (Müller and Jacobs, 2010; Deneris and Wyler, 2012).

The exact mechanism that ensures the production of regionally restricted serotonergic and V3 fates is still poorly understood. Recently, Jacob et al. (2013) have shown that reduced expression of the transcription factor Ascl1 in the spinal cord favors V3 differentiation to the detriment of serotonergic development. However, the intrinsic mechanisms that repress Ascll and exclude 5-HT differentiation from the spinal cord remain to be 
determined. Interestingly, lamprey, fish, and amphibians contain serotonergic neurons in their ventral spinal cord (HarrisWarrick et al., 1985; Branchereau et al., 2000; Lillesaar, 2011), suggesting that the mechanism that prevents $\mathrm{p} 3$ progenitors from differentiating as serotonergic neurons may be specific to the embryonic spinal cord of amniotes.

In this study, we show that the transcription factor Neurog3, which is expressed in the mouse ventral spinal cord (Sommer et al., 1996; Lee et al., 2003) but not in zebrafish spinal cord (Wang et al., 2001), controls the correct specification of p3-derived neurons by suppressing serotonergic neuron production. We provide strong genetic evidence that Neurog 3 ensures the assignment of V3 identity by reducing Ascll expression through a mechanism that involves the transcriptional repressor Hes5. In the absence of Neurog3, spinal p3 progenitors fail to adopt a complete caudal character, which results in heterotopic development of serotonergic neurons at the expense of $\mathrm{V} 3$ interneurons.

\section{Materials and Methods}

Animals. All experiments involving animals were conducted according to the protocols approved by the Institutional Animal Care and Use Committee of the Fundación Instituto Leloir. Genotyping of Neurog3 (Gradwohl et al., 2000), Ascl1 (Guillemot et al., 1993), Nkx2.2 (Briscoe et al., 1999), Ascl1 ${ }^{\mathrm{CreER}}$ (Kim et al., 2011), Sim $1^{\mathrm{Cre}}$ (Zhang et al., 2008), Uncx ${ }^{\text {lacZ }}$ (Mansouri et al., 2000), CAG:CreER (Hayashi and McMahon, 2002), Ascll flox (Pacary et al., 2011), Gata2 ${ }^{\text {GFP }}$ (Suzuki et al., 2006), and Ail4 tdTomato conditional reporter (Madisen et al., 2010) mice were performed by PCR using allele-specific primers for each strain.

Time pregnancies were determined by detection of vaginal plug and midday was designated E0.5. Induction of Cre activity in $A s c l 1^{\mathrm{CreER}}$ mice was achieved by tamoxifen administration (TAM; $150 \mathrm{mg} / \mathrm{kg}$ b.w., i.p.) to pregnant females at the indicated stages.

Embryos were dissected in PBS buffer. After decapitation, embryos were pinned on Sylgard plates, eviscerated, and fixed for $1 \mathrm{~h}$ in $4 \%$ PFA in PBS. They were cryoprotected in $20 \%$ sucrose (overnight, $4^{\circ} \mathrm{C}$ ) before embedding in Cryoplast (Biopack). Stage-matched littermates of desired genotypes were aligned and embedded together to ensure identical processing conditions. Tissue was cryosectioned $30 \mu \mathrm{m}$ thick (Leica 3050S; Leica Biosystems).

In situ hybridization and immunohistochemistry. Nonradioactive in situ hybridization was performed essentially as previously described (Lanuza et al., 2004). Briefly, sections were dried at $55^{\circ} \mathrm{C}$ for $20 \mathrm{~min}$, fixed 15 min with PFA $4 \%$ in PBS, and washed three times with PBS-DEPC. Tissue was treated $3 \mathrm{~min}$ with proteinase $\mathrm{K}(3 \mu \mathrm{g} / \mathrm{ml})$, followed by PFA 4\% $10 \mathrm{~min}$ and three PBS washes. Slides were incubated in triethanolamine-acetic anhydrate $\mathrm{pH} 8.0$ for $10 \mathrm{~min}$, permeabilized with Triton X-100 1\% in PBS for $30 \mathrm{~min}$, and washed with PBS. Sections were incubated for $2 \mathrm{~h}$ with hybridization solution $(50 \%$ formamide, $5 \times \mathrm{SSC}$, $5 \times$ Denhardt solution, and $250 \mu \mathrm{g} / \mathrm{ml}$ yeast tRNA). DIG-labeled RNA probes were generated by in vitro transcription using T7, T3, or sp6 RNA polymerases (Promega), DIG-UTP (Roche), rNTPs (Promega), and PCR-amplified products or linearized plasmids as templates. RNA probes used were mNeurog3 (this study), mSim1 (Zhang et al., 2008), mUncx (Mansouri et al., 2000), mAscll (Kriks et al., 2005), mNkx2.2 (Briscoe et al., 1999), mGata2 (this study), mLmx1b (Cheng et al., 2003),
ratPet1 (Fev; Hendricks et al., 1999), mvGluT2 (Slc17a6; Lanuza et al., 2004), mSerT (Slc6a4; this study), mvGluT3 (Slc17a8; Cheng et al., 2003), mHes5 (Hojo et al., 2000), mvAChT (Slc18a3; Zhang et al., 2008), chickSim1 (this study), chickAscll (Tsarovina et al., 2004), chickNeurog3 (this study), and chickHes5-1 and 5-2 (Fior and Henrique, 2005).

DIG-labeled probes were diluted in hybridization solution, denatured at $80^{\circ} \mathrm{C}$ for $5 \mathrm{~min}$, and added on the slides. Incubation was performed for $14 \mathrm{~h}$ at $68^{\circ} \mathrm{C}$. Sections were washed three times, $45 \mathrm{~min}$, at $68^{\circ} \mathrm{C}$ with $1 \times$ SSC, $50 \%$ formamide. For immunodetection of DIG, slides were blocked with 10\% HI-serum in PBS containing 0.1\% Tween 20 for $1-2 \mathrm{~h}$ (room temperature, RT) and incubated overnight at $4^{\circ} \mathrm{C}$ with alkaline phosphatase-labeled sheep anti-DIG antibody (Roche) diluted in blocking solution. After washing $3 \times 10 \mathrm{~min}$, enzymatic activity was detected by using BCIP $(0.15 \mathrm{mg} / \mathrm{ml}$; Roche $)$ and NBT $(0.18 \mathrm{mg} / \mathrm{ml}$; Roche $)$ in reaction solution (Tris, $\mathrm{pH} 9.5,0.1 \mathrm{M}, \mathrm{MgCl}_{2} 50 \mathrm{~mm}, \mathrm{NaCl} 0.1 \mathrm{M}$, and Tween $200.1 \%$ ). Bright-field pictures were captured by digital camera on Zeiss Axioplan microscope.

Antibody stainings were performed essentially as previously described (Lanuza et al., 2004). Briefly, cryostat sections were washed three times in PBS containing $0.1 \%$ Triton X-100 (PBST) and treated with blocking solution (5\% HI-serum in PBST) for $1 \mathrm{~h}$. Primary antibodies at the appropriate dilutions in blocking solution were incubated overnight at $4^{\circ} \mathrm{C}$. The following antibodies were used: mouse anti-Neurog3, mouse anti-Nkx2.2, mouse anti-Nkx6.1, mouse anti-Isl1/2 (Developmental Studies Hybridoma Bank, DHSB), mouse anti-Ascl1 (BD Biosciences), rabbit anti-Nkx2.2 (Tom Jessell, Columbia University, NY), goat antiSox2 (Santa Cruz Biotechnology), mouse anti- $\beta$ III-tubulin (Sigma), rabbit anti-Olig2 (Millipore Bioscience Research Reagents), mouse antiFoxa2 (Abcam), chicken anti- $\beta$-gal (Abcam), rabbit anti-GFP (Invitrogen), chicken anti-GFP (Aves Laboratories), rabbit anti-dsRed (Clontech), rabbit anti-5HT (ImmunoStar), mouse anti-Cre (Sigma), and rabbit anti-Lhx3 (Sam Pfaff, The Salk Institute, La Jolla, CA).

After incubation, slides were washed $3 \times 10$ min each with PBST and incubated with Cy-labeled, species-specific secondary antibodies (Jackson ImmunoResearch) for $2-3 \mathrm{~h}$ at RT. Sections were dehydrated in ethanol/xylene series and mounted using DPX (Sigma-Aldrich). Images 

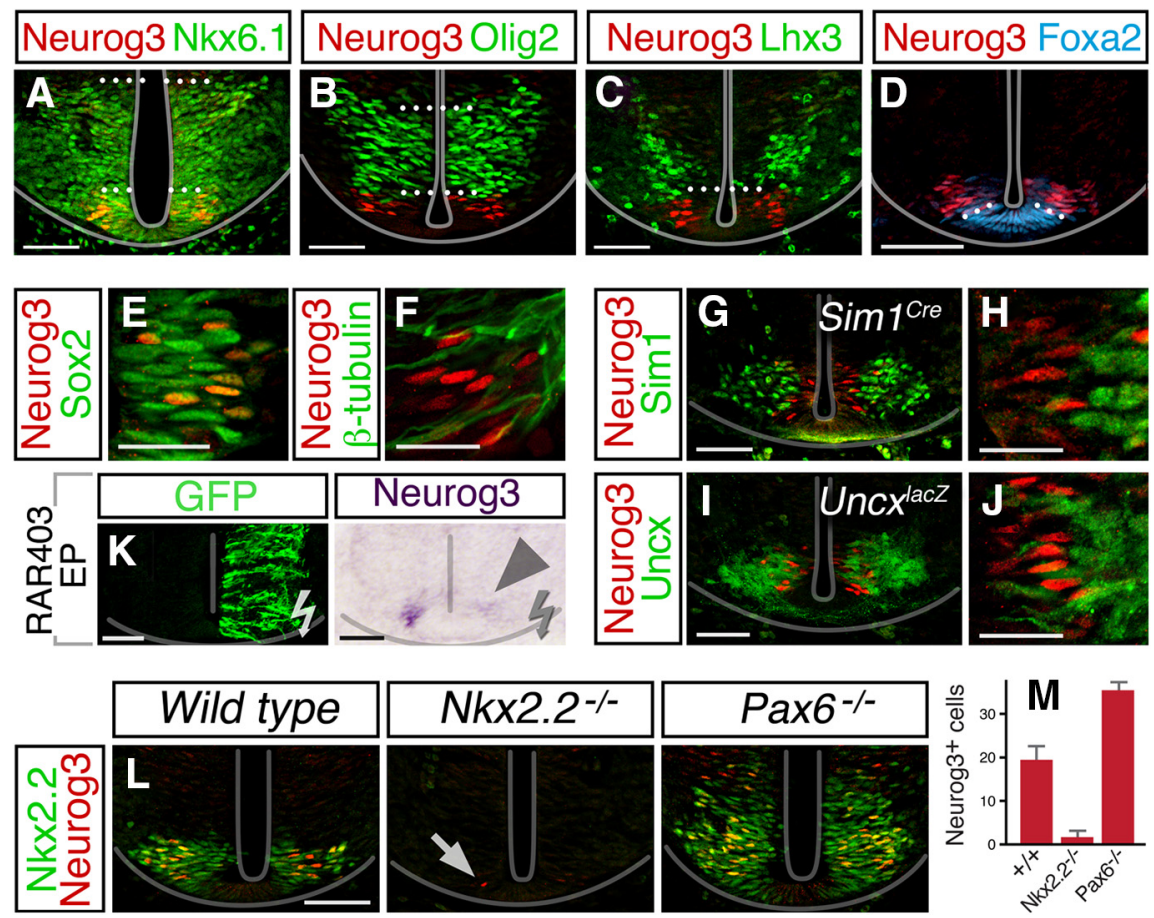

Figure 2. Neurog 3 delineates spinal cord 33 precursors. $A-D$, Neurog 3 is expressed in the spinal $\mathrm{p} 3$ domain. Immunostainings on E10.5 spinal cord sections revealed that Neurog $3^{+}$cells are restricted to Nkx6.1 ${ }^{+}$territories $(\boldsymbol{A})$, ventral to the domain that gives rise to motoneurons, marked by 0 lig2 $(\boldsymbol{B})$ and $\operatorname{Lhx} 3(\boldsymbol{C})$, and excluded from the Foxa2 ${ }^{\mathrm{HIGH}}$ floor plate $(\boldsymbol{D})$. Dotted lines represent dorsoventral boundaries. $\boldsymbol{E}, \boldsymbol{F}$, Neurog 3 is expressed before neuronal differentiation. Immunohistochemistry against Neurog3 on E10.5 spinal cord sections show coexpression with the progenitor marker Sox2 (E), but absence in $\beta$-III-tubulin newborn neurons $(\boldsymbol{F})$. Ventricle to the left. $\mathbf{G}-\boldsymbol{J}$, Neurog3 precedes V3 differentiation. Sim1 (anti-Cre antibody, $\mathbf{G}, \boldsymbol{H}$ ) and Uncx (anti- $\beta$-galactosidase antibody, $I, J$ ) were analyzed in $\operatorname{Sim} 1^{\text {(re/+ }}$ and $U n c x^{\text {lacz/++ }}$ E11.5 spinal cords, respectively. Ventricle to the left in $\boldsymbol{H}$ and $\boldsymbol{J}$. $\boldsymbol{K}$, Neurog3 expression depends on retinoid activity. In situ hybridization with a cNeurog3 probe on $\mathbf{E} 4$ chick spinal cord sections that were electroporated with a dominant-negative RAR403-IRES-GFP expression construct at E3. GFP labeling shows the targeted region. Arrowhead points to Neurog3 reduced expression. $L, M$, Neurog3 expression is regulated by Nkx2.2. Immunostaining against Neurog3 and Nkx2.2 on E10.5 spinal cord sections from wild-type, Nkx2.2, or Pax6 mutant embryos. Nkx2.2 mutants lack Neurog3 in the ventral spinal cord. Arrow points to one Neurog $3^{+}$cell found $(L$, middle). The expanded Nkx2.2 territory in Pax6 mutants induces a dorsal extension of Neurog $3^{+}$cells $\left(\boldsymbol{L}\right.$, right). $\boldsymbol{M}$, Number of Neurog $3^{+}$cells per section. Bars are mean \pm SD. Scale bars: $\boldsymbol{A}-\boldsymbol{D}, \boldsymbol{G}, \boldsymbol{I}, \boldsymbol{K}, \boldsymbol{L}, 50 \mu \mathrm{m} ; \boldsymbol{E}, \boldsymbol{F}, \boldsymbol{H}, \boldsymbol{J}, 20 \mu \mathrm{m}$.

were captured using Zeiss LSM5 Pascal and Zeiss LSM 510 Meta confocal microscopes and assembled using Adobe Photoshop and Adobe Illustrator.

In ovo electroporation. Full-length cDNA of mNeurog3 and cHes5-1 (provided by Domingos Henrique; Fior and Henrique, 2005) were cloned into pCAG-IRES-EGFP vector. Dominant-negative retinoic acid receptor hRAR403 expression plasmid (provided by Shan Sockanathan) and CAG-rAscl1-ires-GFP construct were previously used (Sockanathan et al., 2003; Kriks et al., 2005). Chick electroporation was performed essentially as described previously (Muramatsu et al., 1997).

Quantitations and statistical analysis. At least six sections were examined from each embryo, and no less than three embryos of each genotype were used. Thoracic and upper lumbar spinal cord segments and r6-r7 rhombomeres were analyzed.

Integration of in situ hybridization signals was performed using a MATLAB (The MathWorks) script on nonprocessed images. Background levels were defined by the mean intensity along the perimeter of the selected area and positive pixels were defined as those above background mean +2 standard deviations (SD).

Ascll expression levels were assessed using a MATLAB script that measured the mean intensity of individual nuclei. Ascll intensity of cells located within the $\mathrm{p} 3 / \mathrm{Nkx} 2.2^{+}$domain was corrected by subtracting background levels. For each section, background intensity was determined as the mean intensity of 10 progenitor cells located in the motoneuron progenitor domain (pMN), which do not express Ascl1. A cell was considered "HIGH" when its intensity was above the mean +1 SD of wild-type spinal p3 Ascl1 intensity.
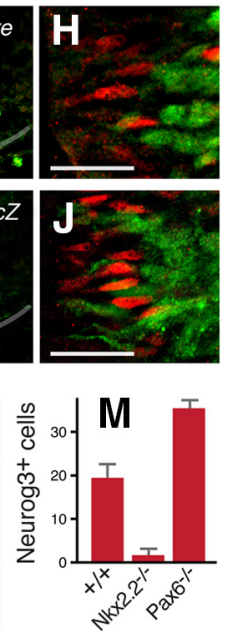

Differences between groups were evaluated by nonparametric Mann-Whitney test or Kruskal-Wallis ANOVA with post hoc Dunn's multiple-comparison test (GraphPad Software). Results were considered statistically significant when $p<0.05$. Data are presented as mean \pm SD.

\section{Results}

Neurogenin 3 is expressed in the spinal cord $\mathrm{p} 3$ domain

Ventral p3 progenitors of the mouse hindbrain and spinal cord produce 5-HT neurons and V3 interneurons, respectively (Fig. $1 A-I$ ). In the developing ventral hindbrain, the expression of the transcription factors Gata2, Lmx1b, and Pet1 delineate the differentiation of serotonergic neurons (Fig. $1 A-D, G$ ), whereas in the spinal cord, Nkx2.2 progenitors produce glutamatergic V3 neurons that are identified by the transcription factors Sim 1 and Uncx (Fig. $1 A, E, F, H$ ). In searching for intrinsic controllers of these divergent neuronal fates, we first explored the spatial and temporal pattern of expression of the bHLH transcription factor Neurog3. In E10.5 embryos, Neurog3 expression was found largely restricted to the most ventral domain of the spinal cord (Fig. $1 K$ ). Immunohistochemical analysis with antibodies against Neurog3 and Nkx2.2 showed that all Neurog3-expressing cells in the developing spinal cord are Nkx2.2 positive (Fig. $1 M, N$ ). Neurog3 is not homogenously expressed in all $\mathrm{Nkx} 2.2^{+}$cells, with Neurog $3^{+}$cells occupying lateral positions within the spinal p3 ventricular zone (Fig. $2 E-J$ ). This suggests that Neurog3 is either oscillatory or preferentially expressed in committed precursors, similar to the expression patterns seen for other bHLH proteins (Bertrand et al., 2002; Imayoshi and Kageyama, 2014). In contrast to the robust expression of Neurog3 in the $\mathrm{p} 3$ domain of the embryonic spinal cord, topographically related p3 progenitors of the hindbrain are negative for Neurog3 (Fig. $1 J-N)$.

In the spinal cord, Neurog3-expressing cells are embedded in Nkx6.1 domains (Fig. 2A), positioned ventral to motoneuron progenitors that are marked by the expression of Olig2 and Lhx3 (Fig. $2 B, C$ ), and excluded from the floor plate (Foxa $2^{\mathrm{HIGH}}$; Fig. $2 D$ ). Neurog 3 expression in the ventral spinal cord is limited to the ventricular zone, as indicated by colabeling with the progenitor cell marker Sox2 (Fig. 2E) and its exclusion from $\beta$ III-tubulin ${ }^{+}$newborn neurons (Fig. 2F). Furthermore, Neurog3 in the p3 domain of the spinal cord precedes the appearance of the transcription factors Siml and Uncx, which are both induced in newly generated neurons as they leave the ventricular zone and acquire postmitotic V3 neuronal identity (Fig. 2G-J). The absence of double labeling of Neurog3 and Cre in the Sim $1^{\text {Cre }}$ neural tube, and Neurog 3 and $\beta$-galactosidase in $U n c x^{\text {lac } Z}$ knockin mice, argues that Neurog3 is rapidly downregulated during V3 neurogenesis.

The limited expression of Neurog3 to the ventrocaudal neural tube suggests that it lays downstream of signals acting along the 
orthogonal axes of the developing nervous system. In view of the preeminent role that retinoid signaling plays in the anteriorposterior patterning of the neural tube and serotonergic neuron development (Muhr et al., 1999; Liu et al., 2001; Maden, 2006; Jacob et al., 2013), we asked if retinoid signaling contributes to restrict Neurog3 to the spinal cord. In keeping with previous experiments showing an anterior-low, posterior-high gradient of retinoic acid in the hindbrain-spinal cord (Maden, 2006; Jacob et al., 2013), electroporation of a dominant-negative version of the retinoic acid receptor (RAR403; Sockanathan et al., 2003) in the chick spinal cord markedly decreased Neurog3 levels (Fig. $2 K$ ), suggesting that Neurog3 is under the control of retinoid signaling. On the other hand, the selective expression of Neurog3 to the most ventral domain of the spinal cord depends on the transcription factor $\mathrm{Nkx} 2.2$, which is induced by sustained Shh signaling (Briscoe et al., 1999; Dessaud et al., 2007). The spinal cord of $N k \times 2.2$ mutants lacks ventral cells that express high levels of Neurog3 (Fig. $2 L, M)$. Conversely, the expansion of the p3/Nkx2.2 ${ }^{+}$domain in Pax6 mutant embryos (Ericson et al., 1997; Briscoe et al., 1999) resulted in an increased number of Neurog $3^{+}$cells that spread dorsally (Fig. $2 L, M)$.

Interplay between Neurog3 and Ascl1 establishes the caudal boundary for serotonergic specification

Recent studies indicate that the expression level of the bHLH transcription factor Ascll strongly influences the choice between serotonergic and V3 cell fates with Ascl1 highly expressed in the hindbrain (Pattyn et al., 2004; Jacob et al., 2013). This suggests that the suppression of Ascll expression in caudal neural tube is a key step in establishing the glutamatergic V3 cell differentiation program. We first compared the expression of Neurog3 and Ascl1 in the p3 domain of the spinal cord throughout development. Neurog3 is initially absent from this domain at E9.5, and begins to be expressed at approximately E10 (Fig. $3 A, D$ ). Ascl1, on the other hand, displays an inverse temporal pattern. It is robustly expressed in $\mathrm{Nkx} 2.2^{+}$spinal cells at E9.5, but is sharply downregulated at later stages (Fig. $3 B, E$ ).

The dynamic pattern of Ascl1 in the developing spinal cord was also analyzed in $A s c l 1^{\text {CreER }}$;CAG:floxstop-tdTomato mice. By retrospectively evaluating Ascl1 expression at E11.5, we detected p3-derived tdTomato ${ }^{+}$cells when tamoxifen was administered at E9.5 (Fig. 3G, arrowhead), but not when induced at E10.5 (Fig. $3 G$ ). This downregulation of Ascl1 in the spinal cord p3 domain contrasts with Ascl1 expression in the hindbrain (Pattyn et al.,

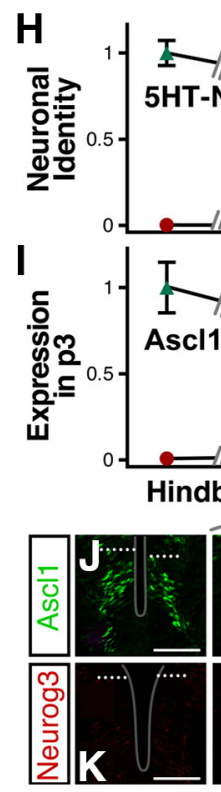

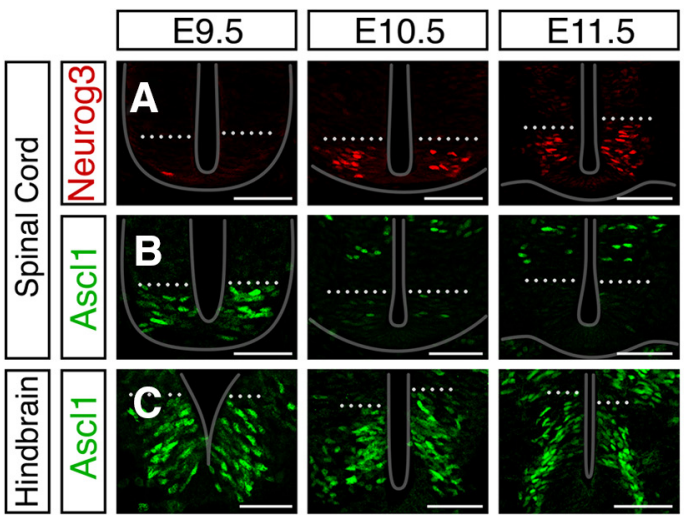
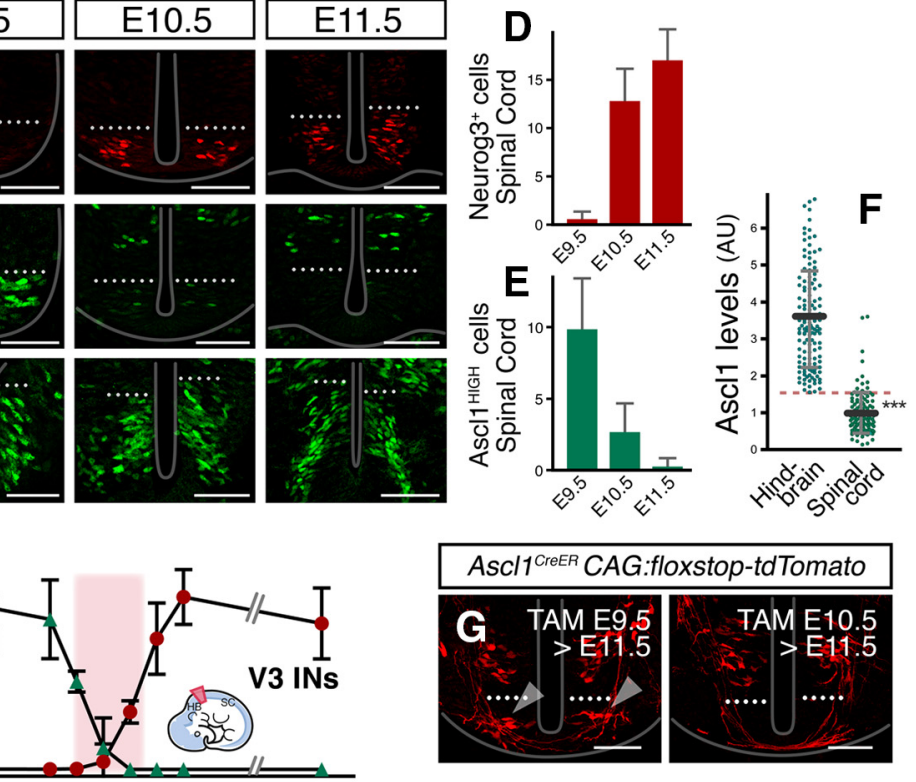

Figure 3. Neurog3 and Ascl1 inversely correlate in the ventral neural tube. $\boldsymbol{A}-\boldsymbol{E}$, Neurog3 and Ascl 1 have a dynamic expression pattern in the ventral spinal cord. Immunohistochemistry against Neurog 3 and Ascl 1 shows that Neurog $3^{+}$cells increase in the $p 3$ domain from E9.5 to E11.5 $(\boldsymbol{A})$, while Ascl1 expression decreases $(\boldsymbol{B})$. Ascl1 in the ventral hindbrain remained constant throughout development (C.D-E, Number of Neurog $3^{+}$or $\mathrm{AsCl}^{\mathrm{HIGH}}$ cells in the spinal cord at the indicated stages. $\boldsymbol{F}$, Measurement of Ascl1 intensity in $\mathrm{p} 3$ progenitors of the hindbrain or spinal cord at E11.5. The dashed line is the threshold for considering cells AsCl1 ${ }^{\mathrm{HIGH}}$ in $\boldsymbol{E}$ (see Materials and Methods); ${ }^{* * *} p<0.001$, Mann-Whitney test. G, Spinal p3 cells express Ascl1 at E9.5 but not at E10.5. In Ascl1 ${ }^{\text {CreER }}$;CAG:floxstop-tdTomato embryos; (re was induced at E9.5 or at E10.5 with TAM. E11.5 spinal cord sections were stained against tdTomato. At E11.5, spinal p3-derived tdTomato ${ }^{+}$cells were found only when (re was activated at E9.5 (arrowhead). $\boldsymbol{H}-\boldsymbol{K}$, Serotonergic and V3 differentiation strictly correlates with Neurog3 and Ascl1-expressing territories. $\boldsymbol{H}, \boldsymbol{I}$, Relative numbers of 33-derived neuron types: serotonergic (5HT-N) or V3 interneurons $(\boldsymbol{H})$ and p3 cells expressing Neurog3 or Ascl $1{ }^{\mathrm{HIGH}}(\boldsymbol{I})$ along the rostrocaudal axis at E11.5. Serotonergic differentiation was determined by GFP-expressing cells in the Nkx2.2 ${ }^{+}$domain of Gata2 $^{\text {GFP }}$ embryos (immunostaining), while V3 interneurons were identified by Sim1 expression (in situ hybridization). The pink area denotes the transition between the hindbrain and the spinal cord shown in the scheme. Cell numbers or signal intensity along the anterior-posterior axis were made relative to the sections with maximum number or maximum intensity. Points are mean \pm SD. $\boldsymbol{J}, \boldsymbol{K}$, Representative images of $\operatorname{Ascl} 1(\boldsymbol{J})$ and Neurog3 $(\boldsymbol{K})$ immunostainings at indicated rostrocaudal coordinates. $\mathbf{L}-\mathbf{0}$, Serotonergic specification is impaired in Ascl1 mutants, while spinal V3 neurons are not affected. In situ hybridizations on E11.5 cross sections. The serotonergic-related transcription factors Gata2 $(\boldsymbol{L})$ and Pet1 $(\boldsymbol{M})$ were not detected in the hindbrain of Ascl1 $^{-/-}$, whereas the V3 identity markers $\operatorname{Sim} 1(\boldsymbol{N})$ and Uncx $(\boldsymbol{O})$ remained unmodified in the spinal cord of Ascl1 mutants. Arrowheads point to $\mathrm{p} 3$ cells $03 \mathrm{p} 3$-derived postmitotic neurons. Bars are mean $\pm \mathrm{SD}$. Dotted lines represent the dorsal boundary of the $\mathrm{Nkx2.2^{+ }}$ domain in the same section. Scale bars: $50 \mu \mathrm{m}$.

2004), where it remains elevated from E9.5 to E11.5 (Fig. 3C). Measurement of Ascl1 intensity in individual p3 cells of the hindbrain and spinal cord at E11.5 reflected quantitative differences in Ascl1 levels (Fig. 3F) as previously shown (Jacob et al., 2013).

We then mapped Neurog3 and Ascl1 expression along the rostrocaudal axis of the E11.5 neural tube. As shown above (Fig. $1 J-N)$, Neurog3 expression was restricted to the spinal cord p3 
chick E3 chick E4 chick E5

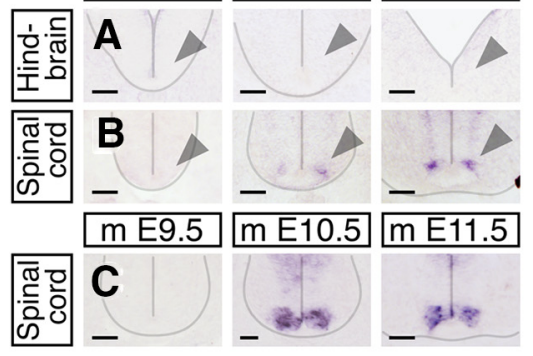

Neurog3-ires-GFP EP

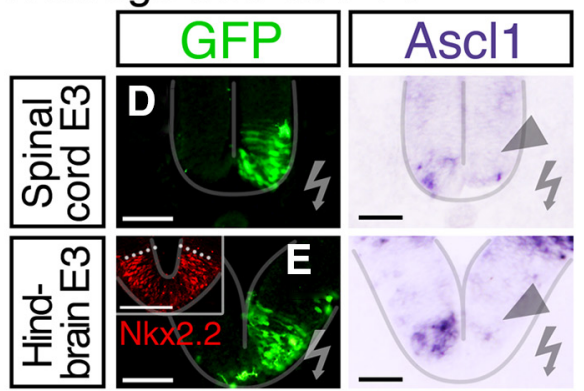

Neurog3-ires-GFP EP

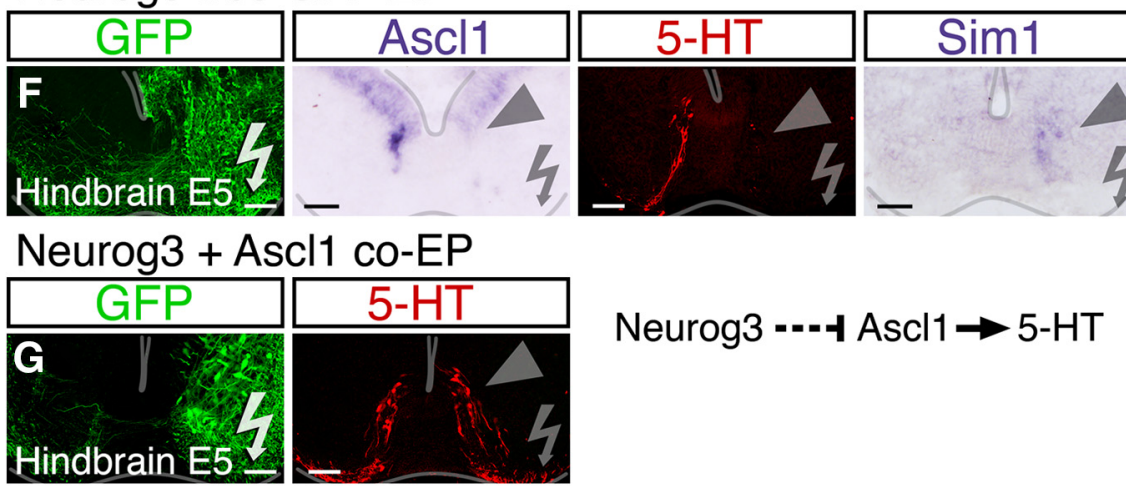

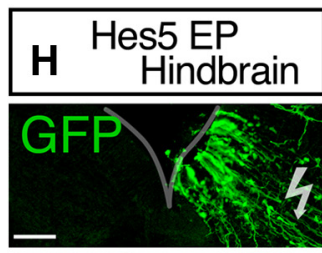

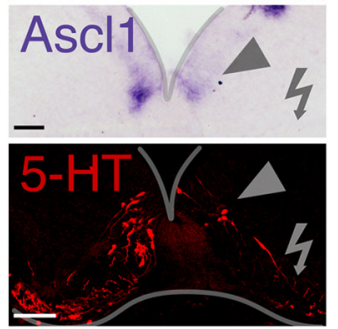

Hes5-IAscl $1 \rightarrow 5-\mathrm{HT}$

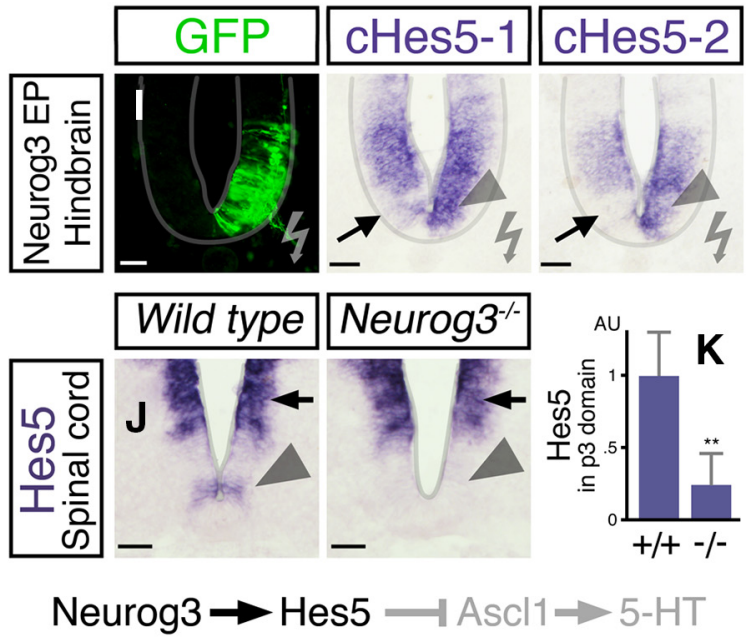

Figure 4. Neurog3 regulates Ascl1 expression by a mechanism involving Hes5. A-C, The spatial and temporal Neurog3 expression pattern is similar in chick and mouse embryos. Sections of chick E3-E5 ventral hindbrain $(\boldsymbol{A})$ and spinal cord $(\boldsymbol{B})$ were hybridized with a probe against cNeurog3. Neurog3 expression was found in the spinal cord beginning at $E 4$, but absent in the ventral hindbrain at all stages. Neurog3 expression pattern in the mouse spinal cord (E9.5-E11.5; $\mathbf{C}$ ) is included for comparison. D, E, Neurog3 represses Ascl1 expression. E2 chick embryos electroporated with Neurog3-IRES-GFP into the ventral spinal cord (D) or hindbrain $(\boldsymbol{E})$ showed reduced Ascl1 mRNA levels analyzed at E3 (arrowheads). No changes were found in Nkx2.2 expression assessed by immunohistochemistry (inset in E). GFP labeling shows targeted region. $\boldsymbol{F}$, Neurog3 misexpression changes neuronal identity in the hindbrain. Cross sections of E5 ventral hindbrain electroporated with Neurog3 were stained with antibodies against GFP and 5-HT, and hybridized with probes against Ascl1 and Sim1. The electroporated side showed reduced Ascl1 levels, suppressed serotonergic specification, and a moderate induction of the V3 neuronal marker Sim1 (arrowheads). G, Coelectroporation of Neurog3 and Ascl1 expression vectors restores 5-HT neuron differentiation in the ventral hindbrain (arrowhead). Cotransfected cross sections of E5 hindbrain were stained with antibodies against GFP and 5-HT. H, Altered neuronal differentiation in the hindbrain after Hes 5 misexpression. Cross sections of E5 chick hindbrain electroporated with Hes5-IRES-GFP were hybridized with an Ascl1 probe and labeled with an antibody against 5 -HT. The electroporated side showed reduced Ascl1 expression and a suppression of serotonergic differentiation. I, Increased Hes 5 levels in the ventral hindbrain after Neurog3 misexpression. E2 chick embryos were electroporated with Neurog3-IRES-GFP and hybridized with CHes5-1 and cHes5-2 probes at E3. In the control side, Hes5 is mildly expressed in the 3 domain (arrow) while induced in the electroporated side (arrowhead). GFP staining reveals the targeted region. $\boldsymbol{J}, \boldsymbol{K}$, Hes 5 expression in the ventral spinal cord depends on Neurog3. E11.5 spinal cord cross sections from wild-type and Neurog3 mutant mice showed reduced Hes5 mRNA levels in the Neurog $3^{-/-}$spinal p3 domain $(\boldsymbol{J})$. Arrowheads point to $\mathrm{p3}$ domain, arrows point to intermediate dorsal progenitors. Quantitation of Hes5 levels in the 3 domain $(\boldsymbol{K})$. Bars aremean \pm SD; ${ }^{* *} p<0.01$,Mann-Whitney test. Schemes of relations between Neurog3, Hes5, Asd1, and differentiation of 5-HT neurons are shown. Scale bars: $50 \mu \mathrm{m}$. domain and excluded from the hindbrain (Fig. 3I). On the contrary, Ascll was robustly expressed in hindbrain $\mathrm{p} 3$ progenitors, and only at low to undetectable levels in spinal p3 ventricular cells (Fig. 3 I, F; Jacob et al., 2013). In the hindbrainspinal cord transition, we observed a sharp inversion in the numbers of Neurog $3^{+}$and Ascll ${ }^{\mathrm{HIGH}}$ cells (Fig. $3 I-K$, pink area), with the Ascl1- and Neurog3-expressing territories strictly corresponding to those that give rise to serotonergic and V3 interneurons, respectively (Fig. 3H).

We then investigated whether this differential anterior-posterior Ascl1 expression correlates with specific and different roles in neuronal specification. Consistent with previous reports that showed that serotonergic differentiation requires Ascll (Pattyn et al., 2004), we found that ventral hindbrain of Ascl1 mutants lack expression of the transcription factors Gata2 and Pet1 (Fig. $3 L, M)$. In contrast, we found that $S i m 1$ and Uncx were largely unaffected in $\mathrm{Ascl}^{-/-}$ spinal cord (Fig. $3 \mathrm{~N}, \mathrm{O}$ ), demonstrating that Ascl1 in the ventral spinal cord is dispensable for V3 interneuron specification.

Together, our results show that early p3 progenitors initially express high levels of Ascll along the entire length of the neural tube, and that the upregulation of Neurog3 in spinal p3 cells coincides with Ascll downregulation. In the hindbrain, the absence of Neurog3 correlates with Ascll maintenance, and the consequent serotonergic differentiation.

Neurog3 represses Ascl1 expression and switches from serotonergic to glutamatergic neurogenesis

To better understand how the complementary Neurog3 and Ascll expression patterns are established, we performed gain-of-function experiments by in ovo electroporation in the chick embryo, where the dynamics of Neurog3 expression is similar to the mouse (Fig. $4 A-C$ ). First, Neurog3 was misexpressed early during spinal cord development, preceding the endogenous induction of Neurog3 (Fig. 4B). Electroporation of a Neurog3IRES-GFP plasmid into E2 chick neural tube reduced ventral spinal cord Ascl1 levels, compared with the contralateral unelectroporated side (Fig. $4 D$ ) or to the electroporation of a control GFP vector (not shown). Furthermore, forced expression of Neurog3 in the ventral hindbrain, where Neurog3 is absent (Fig. 4A), consistently suppressed Ascll expression (Fig. 4E,F), without affecting the dorsoventral extension of the $\mathrm{p} 3$ domain as assessed by Nkx2.2 immunostaining (Fig. 4E, inset). 
As development proceeds, repression of Ascl1 elicited by Neurog3 electroporation in the hindbrain was followed by a marked reduction in the number of serotonergic neurons (Fig. $4 F$ ). In these embryos, the decrease in $5-\mathrm{HT}^{+}$cells was accompanied by the ectopic production of $\mathrm{V} 3-\mathrm{Sim} 1^{+}$neurons in the hindbrain (Fig. 4F). To assess if the reduced serotonergic differentiation induced by Neurog3 required Ascl1 repression, we coelectroporated Neurog3 and Ascl1, and found that serotonergic neurogenesis was restored (Fig. 4G). These results show that ectopic overexpression of Neurog3 in the ventral hindbrain forces the acquisition of a spinal p3 identity in which reduced Ascl1 levels anticipate the suppression of serotonergic specification. Furthermore, the heterochronic expression of Neurog3 in the spinal cord (Fig. 4D) suggests that the role of Neurog3 is to reduce Ascll expression levels in spinal p3 progenitors, which allows the subsequent differentiation of glutamatergic V3 neurons.

\section{Hes5 mediates Neurog3-dependent Ascl1 repression}

To gain further insights into the mechanism underlying Ascl1 repression by Neurog 3 in p3 spinal progenitors, we analyzed Hes proteins, which are transcriptional repressors of Ascl1 that usually act downstream of Notch signaling (Bertrand et al., 2002; Kageyama et al., 2007). The complementary Ascl1 and Hes5 patterns along the p3 domain (Jacob et al., 2013) resemble the reciprocal expression of Ascl1 and Neurog3 (Fig. 3I). This correlation suggests that the modulation of Ascll by Neurog3 in spinal p3 progenitors could functionally involve Hes5.

The electroporation of Hes5 in the developing chick hindbrain was seen to downregulate Ascl1 in the p3 domain and to suppress 5 -HT neuron specification (Fig. 4H). To test whether Neurog 3 could regulate Ascl1 via Hes5, we electroporated Neurog3 in the chick hindbrain and assessed Hes 5 expression. Misexpression of Neurog3 induced Hes5-1 and Hes5-2 expression in the transfected hindbrain p3 domain (Fig. 4I, arrowhead), in contrast to the nonelectroporated side where there is a gap in Hes expression (Fig. 4I, arrow). Interestingly, the induction of Hes 5 by Neurog3 was not restricted to the hindbrain, since Hes 5 upregulation was also evident when Neurog3 was targeted into the spinal cord (data not shown). Consistent with the finding that Neurog3 is able to induce Hes5, Neurog3 mutant embryos show significantly reduced Hes5 levels in the spinal p3 domain (Fig. 4J, arrowhead, $K)$, while its expression in more dorsal ventricular progenitors remained normal (Fig. 4J, arrow). These results provide strong evidence that Hes5 repressor proteins function downstream of
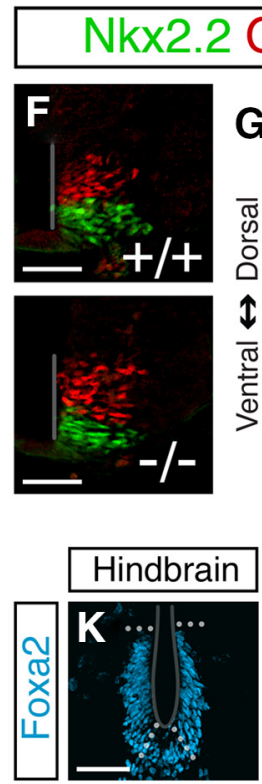
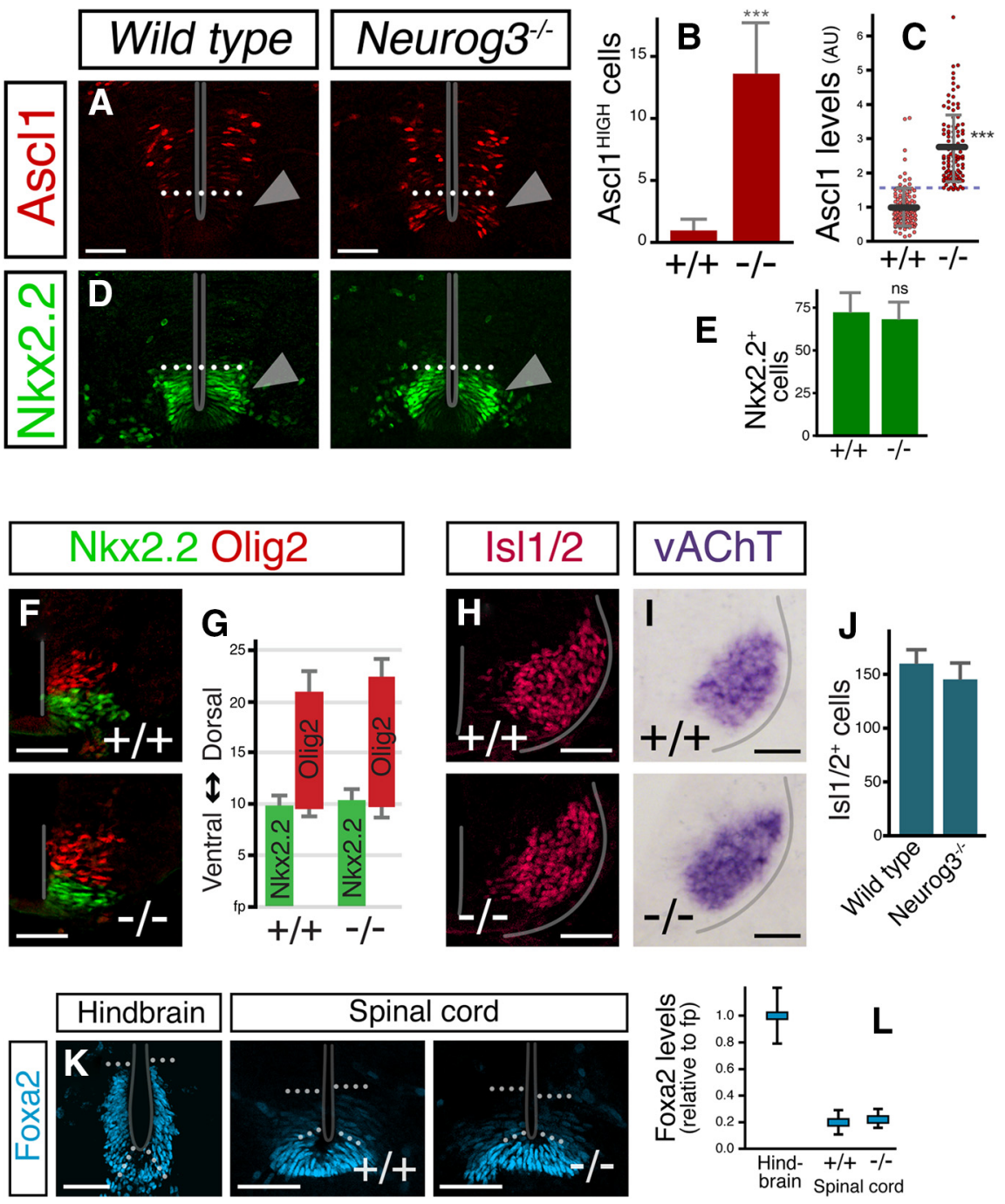

Figure 5. Sustained Ascl1 expression in the Neurog3 mutant spinal cord without changes in dorsoventral patterning. A-E, Neurog3 is necessary to downregulate Ascl 1 in the spinal cord. Wild-type and Neurog $3^{-1-}$ E11.5 sections were stained with antibodies against Ascl1 (A) and Nkx2.2 (D). The number of Ascl1 ${ }^{+}$cells was increased in Neurog $3^{-1-}$ p3 spinal cord (arrowhead, $\boldsymbol{A})$, without changes in the number of Nkx2.2 ${ }^{+}$cells $(\boldsymbol{D})$. Quantitation of the number of Ascl1 ${ }^{\mathrm{HIGH}}(\boldsymbol{B})$ and Nkx2.2 ${ }^{+}(\boldsymbol{E})$ cells in the p3 spinal cord. Bars are mean \pm SD. C, Quantitative differences in Ascl1 intensity in individual p3 progenitor cells of wild-type and Neurog3-null spinal cords. Dashed line indicates the threshold for considering cells as Ascl1 ${ }^{\text {HIGH }}$ in $\boldsymbol{B}_{\text {; }}{ }^{* * *} p<0.001$, MannWhitney test. F, G, Dorsoventral patterning is not affected in Neurog3 mutants. The expression of 0lig2 (pMN domain) and Nkx2.2 (p3 domain) were assessed by immunohistochemistry in Neurog3 mutant E10.5 spinal cords. Dorsoventral positioning of the boundaries was made relative to the length of the ventricular aperture (100\%) in the same sections (G). Boxes are mean limits \pm SD. $\boldsymbol{H}-\boldsymbol{J}$, Motoneuron development is not modified in Neurog $3^{-/-}$. Immunohistochemistry against Is| $1 / 2(\boldsymbol{H})$, in situ hybridization with a probe against the vesicular acetylcholine transporter (vAChT; $I$ ), and quantitation of the number of Isl1/2 ${ }^{+}$cells per hemisection $(\boldsymbol{J})$ of wild-type and Neurog $3^{-/-}$E10.5 spinal cord. $\boldsymbol{K}, \boldsymbol{L}$, Foxa2 expression was unaffected in Neurog $3^{-/-}$spinal cord. Foxa2 was detected by immunohistochemistry on E11.5 hindbrain and spinal cord sections. In the wild-type hindbrain high levels of Foxa2 are found in the p3 domain ( $\boldsymbol{K}$, left), while it is expressed at low levels in the spinal p3 domain of wild-type and Neurog 3 mutants ( $\boldsymbol{K}$, center and right). Quantitation of Foxa2 levels relative to the expression in the floor plate of the same sections ( $\boldsymbol{L}$ ). Boxes are mean \pm SD. Dotted lines indicate the boundaries of the Nkx2.2 ${ }^{+}$territory in the same section. Scale bars: $50 \mu \mathrm{m}$.

Neurog3 to elicit Ascl1 downregulation in p3 spinal progenitors. We propose that this step is necessary to produce the full complement of glutamatergic V3 neurons (see below).

Ascl1 is maintained at high levels in spinal p3 precursors in Neurog3 mutants

To address whether Neurog3 plays a physiological role in regulating Ascll expression in the ventral spinal cord and, in turn, neuron identity, we analyzed the Neurog 3 mutant ventral spinal cord and found a marked increase in the number of cells express- 

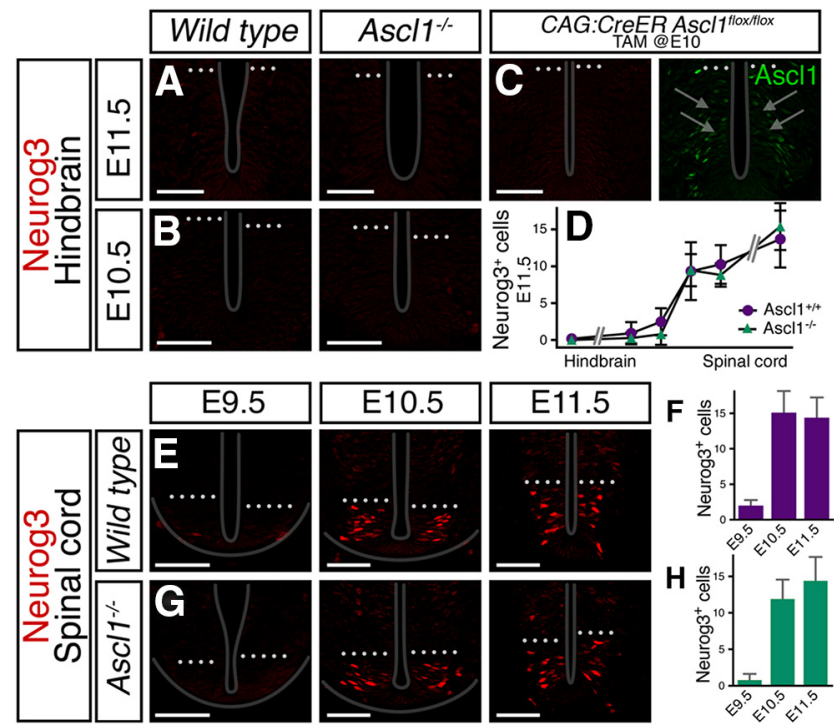

Figure 6. Neurog3-Ascl1 repression is unidirectional. $\boldsymbol{A}-\boldsymbol{D}$, Neurog3 is not expressed in the hindbrain of Ascl1 mutants. E11.5 (A) or E10.5 (B) cross sections of wild-type and Ascl1 ${ }^{-/-}$ hindbrain were stained with an antibody against Neurog3. C, Acute deletion of Ascl1 by TAM at E10 in CAG:CreER;Ascl1 $7^{\text {flox/flox }}$ embryos did not result in Neurog3 expression in the E11.5 hindbrain ( $\boldsymbol{C}$, left). Immunostaining of Ascl1 after TAM induction shows a reduction in Ascl1expressing cells (arrows, $\boldsymbol{C}$, right; see Fig. 3C for comparison). D, The analysis of Neurog3 expression along the anterior-posterior axis of E11.5 wild-type and Ascl1 mutant mice do not show signs of rostral shift in Neurog3 expression. Points are mean \pm SD. Nonsignificant differences were found between groups. $\boldsymbol{E}-\boldsymbol{H}, \mathrm{Ascl} 1$ does not control the onset of Neurog3 in the p3 spinal cord. Cross sections of E9.5, E10.5, and E11.5 spinal cords of wild-type (E) and Ascl1 ${ }^{-/}$ $(\boldsymbol{G})$ mice were stained with an anti-Neurog3 antibody. The appearance of Neurog3 (approximately E10) was not significantly affected in Ascl1 mutants. $\boldsymbol{F}, \boldsymbol{H}$, Quantitation of the number of Neurog $3^{+}$cells at indicated stages in wild-type $(\boldsymbol{F})$ and $A s C 1^{-1-}(\boldsymbol{H})$ spinal cords. Bars are mean \pm SD. Dotted lines represent the dorsal boundary of the Nkx2.2 ${ }^{+}$domain in the same section. Scale bars: $50 \mu \mathrm{m}$.

ing high levels of Ascl1 (Fig. 5A,B). Quantitative analysis in individual spinal cells revealed that Ascl1 levels in Neurog $3^{-/-}$p3 cells are significantly higher than in their wild-type littermates (Fig. 5C) and similar to Ascl1 levels in the p3 hindbrain (Fig. $3 F$ ). This result demonstrates that Neurog3 expression in the spinal cord, which starts around E10 (Fig. $3 A, D$ ), is essential to achieve the low levels of Ascl1 that are a defining feature of spinal p3 progenitors. Interestingly, the loss of Neurog3 does not affect the number of $\mathrm{Nkx} 2.2^{+}$cells in the neural tube (Fig. $5 D, E$ ) nor the position of the p3-pMN boundary (Fig. $5 F, G$ ). Moreover, the motoneuron population in the Neurog $3^{-/-}$spinal cord is not altered (Fig. $5 H-J$ ), and the expression of Foxa2 in p3 cells is retained at low levels, similar to wild types (Fig. $5 K, L$ ). Thus, Neurog3 is not required for dorsoventral identity, but is necessary to limit the expression of Ascl1 in spinal p3 cells, which otherwise would acquire a rostral hindbrain character.

The mutual exclusion between Neurog3 and Ascl1 prompted us to test whether Neurog3 and Ascll function in a crossrepressive fashion. However, we found that the repressive interaction between Neurog3 and Ascl1 is asymmetrical. Neither Ascl1 mutants, nor conditional mutant embryos in which Ascll was acutely deleted by tamoxifen (CAG:CreER;Ascl1 ${ }^{\text {flox/flox }}$ ), showed Neurog 3 expression in the ventral hindbrain (Fig. $6 A-D$ ). In addition, in the Ascl1 mutant spinal cord Neurog3 expression still starts around E10, similar to wild-type embryos (Fig. 6E-H). These experiments rule out a scheme of reciprocal inhibition between Neurog3 and Ascl1, but support a model in which Neurog3 represses Ascl1 in the developing spinal cord.
Neurog3 suppresses 5 -HT fate in the spinal cord

Serotonergic raphe neurons are produced exclusively from ventral hindbrain $\mathrm{p} 3$ progenitors that express the transcription factors Nkx2.2 and Foxa2, which together with Ascl1 are required for their specification (Briscoe et al., 1999; Pattyn et al., 2004; Jacob et al., 2007, 2013). To address whether the persistent Ascl1 expression in the spinal cord of Neurog 3 mutants is indicative of the acquisition of rostral/hindbrain identity, we asked whether spinal progenitors that normally give rise to glutamatergic V3 neurons are redirected into a serotonergic differentiation program.

We found that high levels of Ascl1 in Neurog $3^{-1-}$ spinal p3 cells (Figs. 5A-C, 7A) are closely associated with the ectopic expression of Gata2, Lmx1b, and Pet1 (Fig. $7 B-D$ ), which are key transcription factors of the postmitotic genetic program driving serotonergic fate (Hendricks et al., 1999, Hendricks et al., 2003; Cheng et al., 2003; Ding et al., 2003; Craven et al., 2004) and are never expressed in Nkx2.2-derived cells of the spinal cord (Fig. $1 B-D)$.

The generation of ectopic spinal serotonergic neurons in $\mathrm{Neu}$ rog3 mutants was in all cases entirely restricted to the ventral neuroepithelium. To determine whether ectopic serotonergic neurons in Neurog3-null spinal cords require Nkx2.2, as do 5-HT-neurons in the hindbrain (Briscoe et al., 1999; Cheng et al., 2003; Pattyn et al., 2003), we generated Nkx2.2/Neurog3 and Pax6/Neurog3 double mutants. Nkx2.2/Neurog3 double knockouts did not show signs of ectopic 5-HT neuron differentiation in their spinal cord (Fig. 7E-H). This contrasts starkly with Pax6/ Neurog3 double mutants that have an extended Nkx2.2 ${ }^{+}$domain (Fig. $2 L$ ) and display a $\sim 2$-fold increase in the expression of Ascl1, Gata2, Lmx1b, and Pet1 compared with the simple Neurog3 knock-out (Fig. $7 E-H$ ). Together, these results confirm that ectopic spinal serotonergic neurons originate from $\mathrm{Nkx} 2.2^{+}$cells in the absence of Neurog3. These experiments also demonstrate that spinal p3 cells are bipotential progenitors, which when lacking Neurog 3 adopt the transcriptional program that specifies serotonergic neurons in the ventral hindbrain (Deneris and Wyler, 2012).

To further characterize the heterotopic serotonergic neurons in the spinal cord of Neurog3 mutants, we assessed the presence of 5 -HT and found immunoreactive neurons in the ventral spinal cord of Neurog $3^{-/-}$E12.5 embryos and P0 pups (Fig. 7I,J). $5-\mathrm{HT}^{+}$intraspinal processes were also identified in the ventrolateral funiculus at E12.5 (Fig. 7I, arrows), when hindbrain serotonergic projections have not reached the thoracic and upper lumbar segments analyzed. In addition, inspection of $\mathrm{Neu}$ rog $3^{-1-} \mathrm{P} 0$ animals showed that ectopic $5-\mathrm{HT}^{+}$neurons locate in the ventromedial and ventrolateral spinal cord and project locally through the ventral funiculus (Fig. $7 K-M$ ). Moreover, Neu$\operatorname{rog} 3^{-1-}$ spinal cords display ectopic induction of the serotonin transporter SerT (Fig. $7 N$ ), together with the vesicular glutamate transporter vGluT3 (Fig. 7O), which is a specific marker of 5-HT neurons (Cheng et al., 2003).

Finally, we found that the ectopic generation of serotonergic neurons in the spinal cord of Neurog3 mutants is produced at the expense of glutamatergic V3 interneurons. The analysis of the V3 identity markers Sim 1 and Uncx showed that the spinal cord of Neurog $3^{-/-}$displays a $\sim 50 \%$ reduction in these transcription factors (Fig. 8A,B,D,E; Lee et al., 2003). In addition, the decreased number of glutamatergic V3 neurons in the spinal cord of $\mathrm{Neu}$ rog3 mutants is made evident by a significantly lower expression of the vesicular glutamate transporter vGluT2 (Fig. $8 C, F$ ). In the absence of Neurog3, spinal p3 progenitors produce both V3/ 

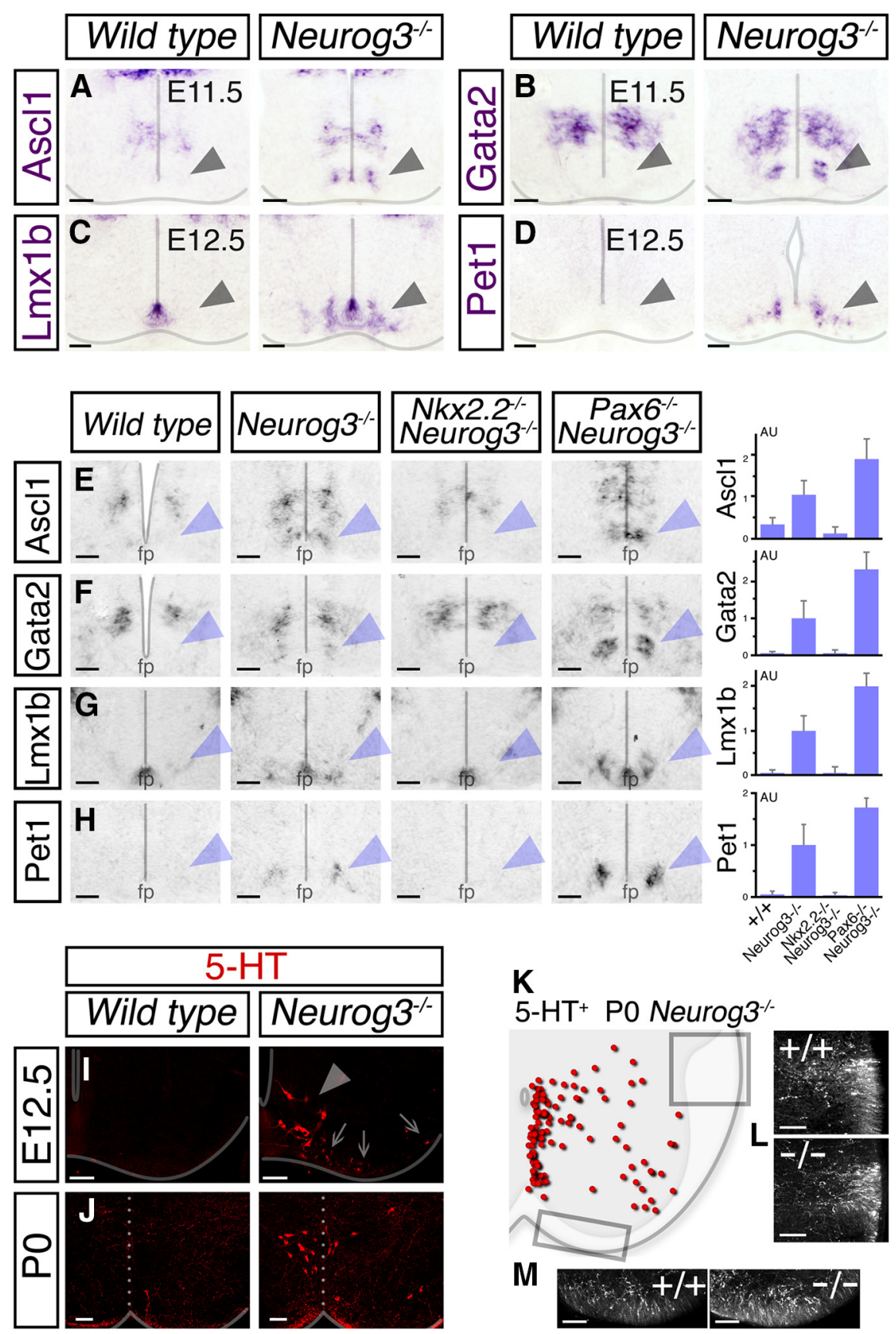

$\mathbf{K}$
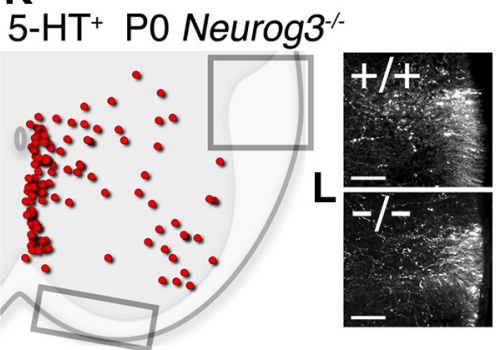

M
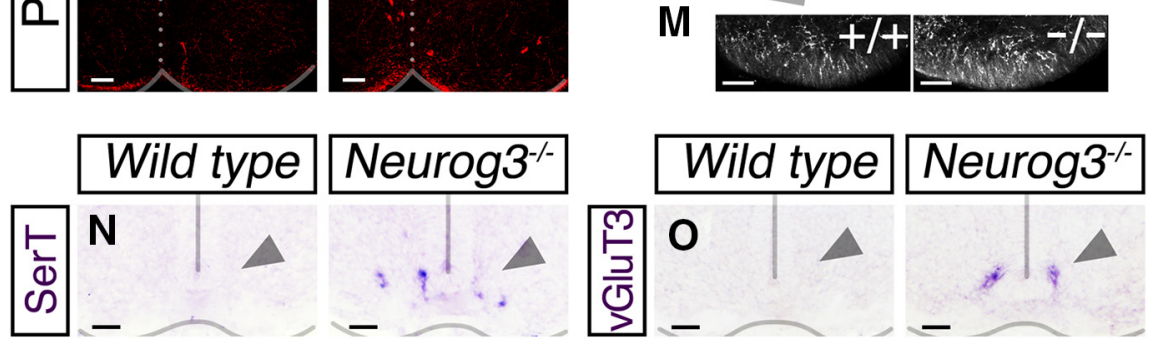

Figure 7. Ectopic serotonergic specification in the spinal cord of Neurog3 mutants. A-D, Induction of 5-HT differentiation program in the spinal cord of Neurog 3 mutants. E11.5 or E12.5 spinal cord sections were hybridized with probes that recognize the serotonergic-related transcription factors Ascl1 (A), Gata2 (B), Lmx1b (C), and Pet1 (D). In all cases a significantly increased expression was found in the mutant spinal $\mathrm{p3}$ domain. $\boldsymbol{E}-\boldsymbol{H}$, The heterotopic serotonergic specification in the spinal cord of Neurog3 mutants requires Nkx2.2. Cross sections of E11.5 spinal cord from wild-type, Neurog $3^{-/-}$, Nkx2.2/Neurog3, and Pax6/ Neurog3 double mutants were analyzed for Ascl1 $(\boldsymbol{E})$, Gata2 $(\boldsymbol{F}), \operatorname{Lmx} 1 \mathrm{~b}(\boldsymbol{G})$, and Pet1 $(\boldsymbol{H})$ expression by in situ hybridization. Quantitations of the signals are shown on the right. Pax6 ${ }^{-1-}$;Neurog $3^{-1-}$ embryos show a $\sim 2$-fold increase in ectopic differentiation of 5-HT neurons in the spinal cord respect to Neurog3 single mutants. Bars are mean \pm SD. Arrowheads point to $\mathrm{p} 3$ progenitors or postmitotic $p 3$-derived neurons. $I-M$, Heterotopic $5-\mathrm{HT}^{+}$neurons in the Neurog $3^{-/-}$spinal cord. Cross sections of E12.5 (I, arrowhead) and PO $(\boldsymbol{J})$ Neurog $3^{-/-}$and wild-type spinal cords were stained with an antibody against 5 -HT. Arrows in $I$ point to cellular processes in the ventrolateral funiculus. $\boldsymbol{K}$, Topological map of serotonergic neurons ( $n=98$ cells) found in P0
Sim $1^{+}$cells and $\mathrm{Gata}^{+} / \mathrm{Pet}^{+}{ }^{+}$serotonergic neurons (Fig. 8G), and later each neuronal population follows distinctive migratory pathways, as shown at E12.5 (Fig. $8 H$ ). It is noteworthy that the position of newly generated ectopic 5-HT neurons at E11.5, proximal to the ventricular zone, may reflect that they are preferentially produced in a delayed neurogenic wave, similar to their development in the hindbrain (Pattyn et al., 2003; Jacob et al., 2007).

\section{Discussion}

In this study, we show that the transcription factor Neurog3 controls cell identity in the $\mathrm{p} 3$ domain of the spinal cord where it suppresses serotonergic specification. The restricted expression of Neurog3 in ventral spinal p3 cells results from the composite activities of ventralizing and caudalizing signals. Neurog3 depends both on $\mathrm{Nkx} 2.2$, in response to high and prolonged Shh signaling (Briscoe et al., 1999; Dessaud et al., 2007), and on retinoids, which encode a caudalizing activity (Muhr et al., 1999; Liu et al., 2001; Maden, 2006). Similar to other bHLH transcription factors (Bertrand et al., 2002; Imayoshi and Kageyama, 2014), Neurog3 appears to be robustly expressed in committed p3 precursors but sharply downregulated when converted into postmitotic V3 neurons.

Both gain- and loss-of-function experiments in the chick and mouse embryo demonstrate that Neurog3 regulates neuronal fate choice in the $\mathrm{p} 3$ progenitor domain by translating regional signals along the anterior-posterior axis into differential Ascll expression (Jacob et al., 2013). Thus, by reducing Ascl1 levels in spinal p3 progenitors, Neurog3 excludes serotonergic differentiation and allows V3 neurogenesis in the spinal cord (Fig. 8I). We propose that the efficient downregulation of Ascl1 and cell fate control by Neurog3 is, at least partially, a non-cell-autonomous process (see Fig. 8I). This mechanism is supported by the observations that Neurog3 is not homogenously expressed in all p3 cells, and that Hes5, a classical target of

Neurog $3^{-/-}$ventral spinal cord. $\boldsymbol{L}, \boldsymbol{M}$, Cross sections of PO spinal cords showing an increased density of $5-\mathrm{HT}^{+}$fibers in ventral funiculus $(\boldsymbol{M})$ but not in lateral funiculus ( $\boldsymbol{L}$; see boxes in $\boldsymbol{K}$ ). $\mathbf{N}, \mathbf{0}$, Cross sections of wild-type and Neurog3-null E12.5 spinal cords were hybridized with probes against the serotonin transporter SerT (Slc6a4, $\boldsymbol{N})$ and the vesicular glutamate trans-

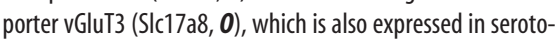
nergic neurons. Arrowheads point to p3-derived neurons. Scale bars: $50 \mu \mathrm{m}$ 

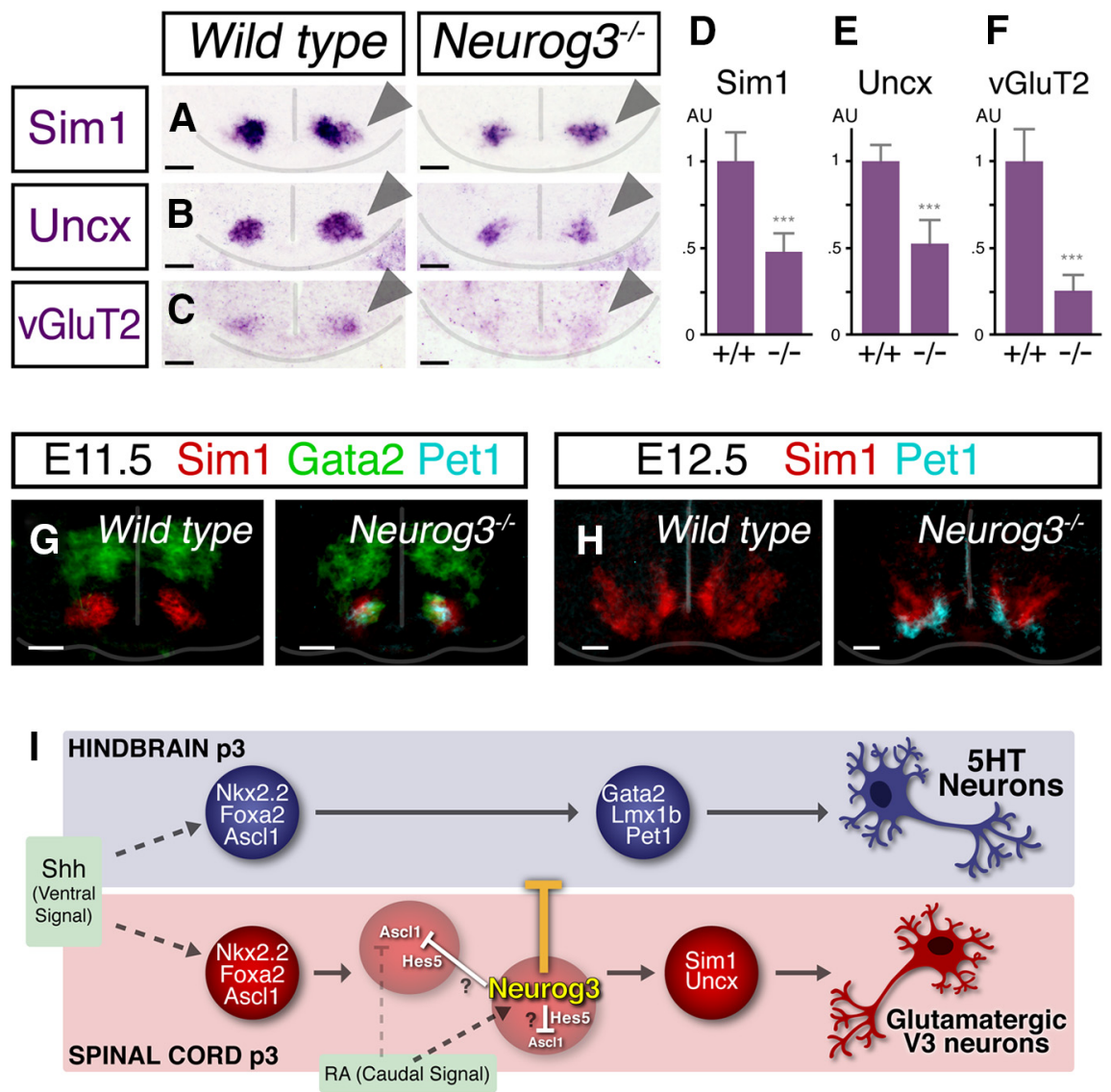

Figure 8. Respecification of ventral neurons in Neurog3 mutant spinal cord. $\boldsymbol{A}-\boldsymbol{F}$, Serotonergic neurons in the Neurog3-null spinal cord are produced at the expense of V3 interneurons. In situ hybridization of Sim1 (A), Uncx (B), and vGluT2 (SIc17a6, C) on E11.5 spinal cord cross sections. Reduced expression was detected in Neurog $3^{-1-}$ spinal cords compared with wild-type littermates $(\boldsymbol{D}-\boldsymbol{F})$. Bars are mean $\pm S D ;{ }^{* *} p<0.001$, Mann-Whitney test. Arrowheads point to $\mathrm{p} 3$ progenitor cells or postmitotic neurons generated from this domain. $\mathbf{G}, \boldsymbol{H}$, Ectopic 5 -HT neurons as well as a reduced V3 population arise from Neurog $3^{-/}$ p3 domain, and segregate afterward. Wild-type and Neurog $3^{-1-}$ spinal cord cross sections were hybridized with Gata2, Sim1, and Pet1 probes at E11.5 $(\boldsymbol{G})$ and E12.5 $(\boldsymbol{H})$. Signals from adjacent sections were overlaid and pseudocolored. AtE11.5 newborn ectopic Gata2/Pet1-expressing cells and Sim $1^{+}$neurons emanate both from p3 progenitors (G). By E12.5 each population occupies different regions: Pet ${ }^{+}{ }^{+}$neurons are found adjacent to the ventrolateral funiculus while $\operatorname{Sim} 1{ }^{+}$neurons distribute throughout the ventromedial spinal cord $(\boldsymbol{H})$. Scale bars: $50 \mu \mathrm{m}$. $\boldsymbol{I}$, Scheme of neuronal specification in the p3 domain of the hindbrain and spinal cord, and the role of the transcription factor Neurog3 in restricting serotonergic neuron differentiation to the hindbrain. Ventral signals (Shh) induce the expression of common transcriptional regulators in both the hindbrain and the spinal cord p3 early progenitors. Caudalizing signals, such as RA, induce the onset of Neurog 3 in p3 precursors of the spinal cord. Neurog3 represses Ascl1 through a process mediated by Hes genes and thus prevents serotonergic specification in the spinal cord. Neurog3dependent downregulation of Ascl1 is likely to involve cell-cell interactions within the spinal $\mathrm{p} 3$ domain.

Notch signaling, is responsible for Ascl1 transcriptional repression in the $\mathrm{p} 3$ domain.

Our results show that in the absence of Neurog3, spinal p3 cells produce serotonergic neurons. However, some V3 interneurons do differentiate in the Neurog $3^{-/-}$spinal cord. This incomplete conversion can be explained by Ascl1 not being equally de-repressed in all spinal p3 cells (Fig. 5). It is possible that other caudalizing signals (Jacob et al., 2013), still present in Neurog3 mutants, normally operate together with Neurog3 to achieve low Ascll expression and secure the exclusion of 5-HT neurons from the spinal cord (Fig. 8I). Nevertheless it remains possible that the incomplete neuronal fate change reflects the existence of $\mathrm{p} 3$ cell subpopulations or temporally coordinated neurogenic waves whose specification programs are differentially affected by the loss of Neurog3.

The results presented favor the notion that Neurog3 function is to suppress Ascll expression and 5-HT neurogenesis in the

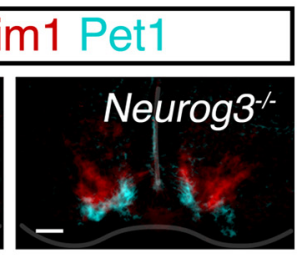

spinal cord, rather than instructing V3 differentiation. Actually, Neurog3 is not strictly required for $\mathrm{V} 3$ interneuron specification, as some $\mathrm{V} 3$ interneurons are still generated in $N e u r o g 3^{-/-}$spinal cords (Fig. 8A-F). The reduction observed in V3 numbers in Neurog3 mutants can be attributed to spinal $\mathrm{p} 3$ progenitors acquiring a serotonergic fate (Fig. 5, 7). Nevertheless, we cannot rule out that Neurog3 may be additionally required to acquire a complete V3 character including neurotransmitter identity, since vGluT2 expression is more strongly affected by Neurog3 loss compared with Sim1 and Uncx (Fig. 8A-F).

In other systems, Neurog3 is a known genetic switch that balances between alternative cell fates from pluripotent progenitors. In the pancreas Neurog3 specifies endocrine against exocrine fates from multipotent pancreatic progenitors (Gradwohl et al., 2000). In the hypothalamus, Neurog3 selects POMC at the expense of NPY and TH neurons (Pelling et al., 2011). In contrast to these roles, our experiments suggest a novel function for Neurog3, in which it provides distinct regional identities to spinal cord and hindbrain p3 progenitors. In this context, Neurog3, together with differential retinoid activity (Jacob et al., 2013), serves as a mechanism for interpreting anteriorposterior positioning to impose the caudal border for the serotonergic system in amniotes.

In the mammalian central nervous system serotonergic neurons are found exclusively in the raphe nuclei. In contrast, aquatic vertebrates, including the lamprey, fish, and amphibians, contain both the brainstem raphe system and 5-HT cells embedded in the spinal cord motor networks (Harris-Warrick et al., 1985; Branchereau et al., 2000; Lillesaar, 2011). In the vertebrate spinal cord, 5-HT plays an important role in organizing the locomotor pattern and can profoundly modulate the motor output (Schmidt and Jordan, 2000). However, the functional significance of local intraspinal serotonergic neurons is unclear, but might be related to phylogenetic locomotor modalities. In species lacking an intrinsic serotonergic spinal system, such as mammals, these functions may have been lost or may have been co-opted by raphe 5-HT descending projections. We hypothesize that the expression of Neu$\operatorname{rog} 3$ in the embryonic spinal cord is important in this evolutionary change. Supporting this proposal, studies in zebrafish have shown that Neurog3 is not expressed in the developing spinal cord (Wang et al., 2001). The absence of Neurog3 correlates with the production of Pet1-expressing $5-\mathrm{HT}^{+}$neurons in the ventromedial spinal cord of zebrafish larvae (McLean and Fetcho, 2004; Lillesaar et al., 2009).

In summary, our study demonstrates that spinal $\mathrm{p} 3$ progenitors have the potential to produce serotonergic and V3 interneu- 
rons, with the expression of Neurog 3 being sufficient to suppress the transcriptional program that supports 5-HT neuron development. Neurog3 restricts serotonergic development to the hindbrain and allows the production of a complete cohort of glutamatergic V3 interneurons necessary to establish robust and balanced spinal locomotor rhythms (Zhang et al., 2008; Borowska et al., 2013).

\section{References}

Bertrand N, Castro DS, Guillemot F (2002) Proneural genes and the specification of neural cell types. Nat Rev Neurosci 3:517-530. CrossRef Medline

Borowska J, Jones CT, Zhang H, Blacklaws J, Goulding M, Zhang Y (2013) Functional subpopulations of V3 interneurons in the mature mouse spinal cord. J Neurosci 33:18553-18565. CrossRef Medline

Branchereau P, Rodriguez JJ, Delvolvé I, Abrous DN, Le Moal M, Cabelguen JM (2000) Serotonergic systems in the spinal cord of the amphibian urodele Pleurodeles waltl. J Comp Neurol 419:49-60. CrossRef Medline

Briscoe J, Novitch BG (2008) Regulatory pathways linking progenitor patterning, cell fates and neurogenesis in the ventral neural tube. Philos Trans R Soc Lond B Biol Sci 363:57-70. CrossRef Medline

Briscoe J, Sussel L, Serup P, Hartigan-O’Connor D, Jessell TM, Rubenstein JL, Ericson J (1999) Homeobox gene Nkx2.2 and specification of neuronal identity by graded Sonic hedgehog signalling. Nature 398:622-627. CrossRef Medline

Cheng L, Chen CL, Luo P, Tan M, Qiu M, Johnson R, Ma Q (2003) Lmx1b, Pet-1, and Nkx2.2 coordinately specify serotonergic neurotransmitter phenotype. J Neurosci 23:9961-9967. Medline

Craven SE, Lim KC, Ye W, Engel JD, de Sauvage F, Rosenthal A (2004) Gata2 specifies serotonergic neurons downstream of sonic hedgehog. Development 131:1165-1173. CrossRef Medline

Deneris ES, Wyler SC (2012) Serotonergic transcriptional networks and potential importance to mental health. Nat Neurosci 15:519-527. CrossRef Medline

Dessaud E, Yang LL, Hill K, Cox B, Ulloa F, Ribeiro A, Mynett A, Novitch BG, Briscoe J (2007) Interpretation of the sonic hedgehog morphogen gradient by a temporal adaptation mechanism. Nature 450:717-720. CrossRef Medline

Ding YQ, Marklund U, Yuan W, Yin J, Wegman L, Ericson J, Deneris E, Johnson RL, Chen ZF (2003) Lmx1b is essential for the development of serotonergic neurons. Nat Neurosci 6:933-938. CrossRef Medline

Ericson J, Rashbass P, Schedl A, Brenner-Morton S, Kawakami A, van Heyningen V, Jessell TM, Briscoe J (1997) Pax6 controls progenitor cell identity and neuronal fate in response to graded Shh signaling. Cell 90: 169-180. CrossRef Medline

Fior R, Henrique D (2005) A novel hes5/hes6 circuitry of negative regulation controls Notch activity during neurogenesis. Dev Biol 281:318-333. CrossRef Medline

Goulding M (2009) Circuits controlling vertebrate locomotion: moving in a new direction. Nat Rev Neurosci 10:507-518. CrossRef Medline

Gradwohl G, Dierich A, LeMeur M, Guillemot F (2000) neurogenin3 is required for the development of the four endocrine cell lineages of the pancreas. Proc Natl Acad Sci U S A 97:1607-1611. CrossRef Medline

Gray PA (2008) Transcription factors and the genetic organization of brain stem respiratory neurons. J Appl Physiol 104:1513-1521. CrossRef Medline

Guillemot F, Lo LC, Johnson JE, Auerbach A, Anderson DJ, Joyner AL (1993) Mammalian achaete-scute homolog 1 is required for the early development of olfactory and autonomic neurons. Cell 75:463-476. CrossRef Medline

Harris-Warrick RM, McPhee JC, Filler JA (1985) Distribution of serotonergic neurons and processes in the lamprey spinal cord. Neuroscience 14: 1127-1140. CrossRef Medline

Hayashi S, McMahon AP (2002) Efficient recombination in diverse tissues by a tamoxifen-inducible form of Cre: a tool for temporally regulated gene activation/inactivation in the mouse. Dev Biol 244:305-318. CrossRef Medline

Hendricks TJ, Fyodorov DV, Wegman LJ, Lelutiu NB, Pehek EA, Yamamoto B, Silver J, Weeber EJ, Sweatt JD, Deneris ES (2003) Pet-1 ETS gene plays a critical role in 5-HT neuron development and is required for normal anxiety-like and aggressive behavior. Neuron 37:233-247. CrossRef Medline
Hendricks T, Francis N, Fyodorov D, Deneris ES (1999) The ETS domain factor Pet-1 is an early and precise marker of central serotonin neurons and interacts with a conserved element in serotonergic genes. J Neurosci 19:10348-10356. Medline

Hojo M, Ohtsuka T, Hashimoto N, Gradwohl G, Guillemot F, Kageyama R (2000) Glial cell fate specification modulated by the bHLH gene Hes5 in mouse retina. Development 127:2515-2522. Medline

Imayoshi I, Kageyama R (2014) bHLH factors in self-renewal, multipotency, and fate choice of neural progenitor cells. Neuron 82:9-23. CrossRef Medline

Jacob J, Ferri AL, Milton C, Prin F, Pla P, Lin W, Gavalas A, Ang SL, Briscoe J (2007) Transcriptional repression coordinates the temporal switch from motor to serotonergic neurogenesis. Nat Neurosci 10:1433-1439. CrossRef Medline

Jacob J, Kong J, Moore S, Milton C, Sasai N, Gonzalez-Quevedo R, Terriente J, Imayoshi I, Kageyama R, Wilkinson DG, Novitch BG, Briscoe J (2013) Retinoid acid specifies neuronal identity through graded expression of Ascl1. Curr Biol 23:412-418. CrossRef Medline

Jessell TM (2000) Neuronal specification in the spinal cord: inductive signals and transcriptional codes. Nat Rev Genet 1:20-29. CrossRef Medline

Kageyama R, Ohtsuka T, Kobayashi T (2007) The Hes gene family: repressors and oscillators that orchestrate embryogenesis. Development 134: 1243-1251. CrossRef Medline

Kim EJ, Ables JL, Dickel LK, Eisch AJ, Johnson JE (2011) Ascl1 (Mash1) defines cells with long-term neurogenic potential in subgranular and subventricular zones in adult mouse brain. PLoS One 6:e18472. CrossRef Medline

Kriks S, Lanuza GM, Mizuguchi R, Nakafuku M, Goulding M (2005) Gsh2 is required for the repression of Ngn1 and specification of dorsal interneuron fate in the spinal cord. Development 132:2991-3002. CrossRef Medline

Lanuza GM, Gosgnach S, Pierani A, Jessell TM, Goulding M (2004) Genetic identification of spinal interneurons that coordinate left-right locomotor activity necessary for walking movements. Neuron 42:375-386. CrossRef Medline

Lee J, Wu Y, Qi Y, Xue H, Liu Y, Scheel D, German M, Qiu M, Guillemot F, Rao M, Gradwohl G (2003) Neurogenin3 participates in gliogenesis in the developing vertebrate spinal cord. Dev Biol 253:84-98. CrossRef Medline

Lillesaar C (2011) The serotonergic system in fish. J Chem Neuroanat 41: 294-308. CrossRef Medline

Lillesaar C, Stigloher C, Tannhäuser B, Wullimann MF, Bally-Cuif L (2009) Axonal projections originating from raphe serotonergic neurons in the developing and adult zebrafish, Danio rerio, using transgenics to visualize raphe-specific pet1 expression. J Comp Neurol 512:158-182. CrossRef Medline

Liu JP, Laufer E, Jessell TM (2001) Assigning the positional identity of spinal motor neurons: rostrocaudal patterning of Hox-c expression by FGFs, Gdf11, and retinoids. Neuron 32:997-1012. CrossRef Medline

Maden M (2006) Retinoids and spinal cord development. J Neurobiol 66: 726-738. CrossRef Medline

Madisen L, Zwingman TA, Sunkin SM, Oh SW, Zariwala HA, Gu H, Ng LL, Palmiter RD, Hawrylycz MJ, Jones AR, Lein ES, Zeng H (2010) A robust and high-throughput Cre reporting and characterization system for the whole mouse brain. Nat Neurosci 13:133-140. CrossRef Medline

Mansouri A, Voss AK, Thomas T, Yokota Y, Gruss P (2000) Uncx4.1 is required for the formation of the pedicles and proximal ribs and acts upstream of Pax9. Development 127:2251-2258. Medline

McLean DL, Fetcho JR (2004) Ontogeny and innervation patterns of dopaminergic, noradrenergic, and serotonergic neurons in larval zebrafish. J Comp Neurol 480:38-56. CrossRef Medline

Muhr J, Graziano E, Wilson S, Jessell TM, Edlund T (1999) Convergent inductive signals specify midbrain, hindbrain, and spinal cord identity in gastrula stage chick embryos. Neuron 23:689-702. CrossRef Medline

Müller CP, Jacobs BL (2010) Handbook of the behavioral neurobiology of serotonin. Amsterdam: Academic/Elsevier.

Muramatsu T, Mizutani Y, Ohmori Y, Okumura J (1997) Comparison of three nonviral transfection methods for foreign gene expression in early chicken embryos in ovo. Biochem Biophys Res Commun 230:376-380. CrossRef Medline

Pacary E, Heng J, Azzarelli R, Riou P, Castro D, Lebel-Potter M, Parras C, Bell DM, Ridley AJ, Parsons M, Guillemot F (2011) Proneural transcription 
factors regulate different steps of cortical neuron migration through Rndmediated inhibition of RhoA signaling. Neuron 69:1069-1084. CrossRef Medline

Pattyn A, Vallstedt A, Dias JM, Samad OA, Krumlauf R, Rijli FM, Brunet JF, Ericson J (2003) Coordinated temporal and spatial control of motor neuron and serotonergic neuron generation from a common pool of CNS progenitors. Genes Dev 17:729-737. CrossRef Medline

Pattyn A, Simplicio N, van Doorninck JH, Goridis C, Guillemot F, Brunet JF (2004) Ascl1/Mash1 is required for the development of central serotonergic neurons. Nat Neurosci 7:589-595. CrossRef Medline

Pelling M, Anthwal N, McNay D, Gradwohl G, Leiter AB, Guillemot F, Ang SL (2011) Differential requirements for neurogenin 3 in the development of POMC and NPY neurons in the hypothalamus. Dev Biol 349:406-416. CrossRef Medline

Schmidt BJ, Jordan LM (2000) The role of serotonin in reflex modulation and locomotor rhythm production in the mammalian spinal cord. Brain Res Bull 53:689-710. CrossRef Medline

Sockanathan S, Perlmann T, Jessell TM (2003) Retinoid receptor signaling in postmitotic motor neurons regulates rostrocaudal positional identity and axonal projection pattern. Neuron 40:97-111. CrossRef Medline
Sommer L, Ma Q, Anderson DJ (1996) neurogenins, a novel family of atonal-related bHLH transcription factors, are putative mammalian neuronal determination genes that reveal progenitor cell heterogeneity in the developing CNS and PNS. Mol Cell Neurosci 8:221-241. CrossRef Medline

Suzuki N, Ohneda O, Minegishi N, Nishikawa M, Ohta T, Takahashi S, Engel JD, Yamamoto M (2006) Combinatorial Gata2 and Sca1 expression defines hematopoietic stem cells in the bone marrow niche. Proc Natl Acad Sci U S A 103:2202-2207. CrossRef Medline

Tsarovina K, Pattyn A, Stubbusch J, Müller F, van der Wees J, Schneider C, Brunet JF, Rohrer H (2004) Essential role of Gata transcription factors in sympathetic neuron development. Development 131:4775-4786. CrossRef Medline

Wang X, Chu LT, He J, Emelyanov A, Korzh V, Gong Z (2001) A novel zebrafish bHLH gene, neurogenin3, is expressed in the hypothalamus. Gene 275:47-55. CrossRef Medline

Zhang Y, Narayan S, Geiman E, Lanuza GM, Velasquez T, Shanks B, Akay T, Dyck J, Pearson K, Gosgnach S, Fan CM, Goulding M (2008) V3 spinal neurons establish a robust and balanced locomotor rhythm during walking. Neuron 60:84-96. CrossRef Medline 